\title{
CARACTERIZAÇÃO MICROESTRUTURAL DE TUBO EXTRUDADO DA LIGA DE ALUMÍNIO AA 6351*
}

\author{
Wei Tsu Jinan ${ }^{1}$ \\ José Veríssimo Silva dos Santos ${ }^{2}$ \\ Angelo Fernando Padilha ${ }^{3}$
}

\begin{abstract}
Resumo
A liga de alumínio AA 6351 é uma liga endurecível por precipitação coerente do sistema Al-Si-Mg, contendo adicionalmente $\mathrm{Mn}$ e Fe. Neste trabalho foi realizada a caracterização microestrutural de um tubo extrudado de parede grossa da liga AA 6351. Foram utilizadas várias técnicas complementares de caracterização microestrutural, tais como microscopia óptica de luz polarizada, microscopia eletrônica de varredura eletrônica (MEV), espectroscopia de raios X por dispersão de energia (EDS), difração de elétrons retroespalhados (EBSD), medidas de dureza e de condutividade elétrica. Foram analisadas as principais características dos grãos e precipitados presentes. Foi detectada e analisada uma zona periférica de grãos grosseiros nas proximidades das superfícies externa e interna do tubo.
\end{abstract}

Palavras-chave: Liga de alumínio AA 6351; Extrusão; Caracterização microstructural; Zona periférica de grãos grosseiros.

\section{MICROSTRUCTURAL CHARACTERIZATION OF AN EXTRUDED TUBE OF ALUMINUM ALLOY AA 6351}

\begin{abstract}
The aluminum alloy AA 6351 is a precipitation hardening alloy of the Al-Mg-Si system, additionally containing $\mathrm{Mn}$ and $\mathrm{Fe}$. In this work was carried out the microstructural characterization of a thick wall extruded tube of the AA 6351. Several complementary techniques of microstructural characterization were used, such as polarized light optical microscopy, electronic scanning electron microscopy (SEM), energy dispersive X-ray spectroscopy (EDS), backscattered electron diffraction (EBSD), measurements of hardness and electrical conductivity. The main characteristics of the grains and precipitates were analyzed. A peripheral zone of coarse grains was detected and analyzed in the vicinity of the outer and inner surfaces of the tube.
\end{abstract}

Keywords: Aluminum alloy AA 6351; Extrusion; Microstructural characterization; Peripheral zone of coarse grains.

1 Engenheira de Materiais, Pós-graduanda, Departamento de Engenharia Metalúrgica e de Materiais da Escola Politécnica da Universidade de São Paulo (EPUSP), São Paulo, SP, Brasil.

2 Tecnólogo em Processos Metalúrgicos, Departamento de Engenharia Metalúrgica e de Materiais da Escola Politécnica da Universidade de São Paulo (EPUSP), São Paulo, SP, Brasil

3 Professor Titular, Departamento de Engenharia Metalúrgica e de Materiais da Escola Politécnica da Universidade de São Paulo (EPUSP), São Paulo, SP, Brasil 


\section{INTRODUÇÃO}

A liga de alumínio AA 6351 é uma liga endurecível por precipitação coerente do sistema Al-Si-Mg, contendo no total cerca de $2,5 \%$ em massa de soluto. Além de $\mathrm{Si}$ $(0,7$ a $1,3 \%), M g(0,4$ a $0,8 \%)$ e $M n(0,4$ a $0,8 \%)$, esta liga apresenta frequentemente em sua composição química $\mathrm{Fe}$ (máx. 0,5\%). O sistema Al-Mg-Si é em geral representado [1] na forma do sistema pseudo binário $\mathrm{Al}-\mathrm{Mg}_{2} \mathrm{Si}$, onde se pode observar um eutético a $595^{\circ} \mathrm{C}$ e solubilidade máxima de $1,18 \%$ em massa de $\mathrm{Mg}_{2} \mathrm{Si}$ (vide Figura 1). Apesar de ser tradicionalmente aceito que os precipitados endurecedores de ligas do sistema Al-Mg-Si apresentam a estequiometria de 2:1 $\left(\mathrm{Mg}_{2} \mathrm{Si}\right)$, estudos recentes [1] evidenciaram que os precipitados se formam na estequiometria de 1:1 (MgSi), ou seja, a razão de $\mathrm{Mg}$ e Si adicionados à liga deveria ser aproximadamente de 1:1, o que levou ao desenvolvimento de ligas com menor razão Mg:Si e maior extrudabilidade [1].

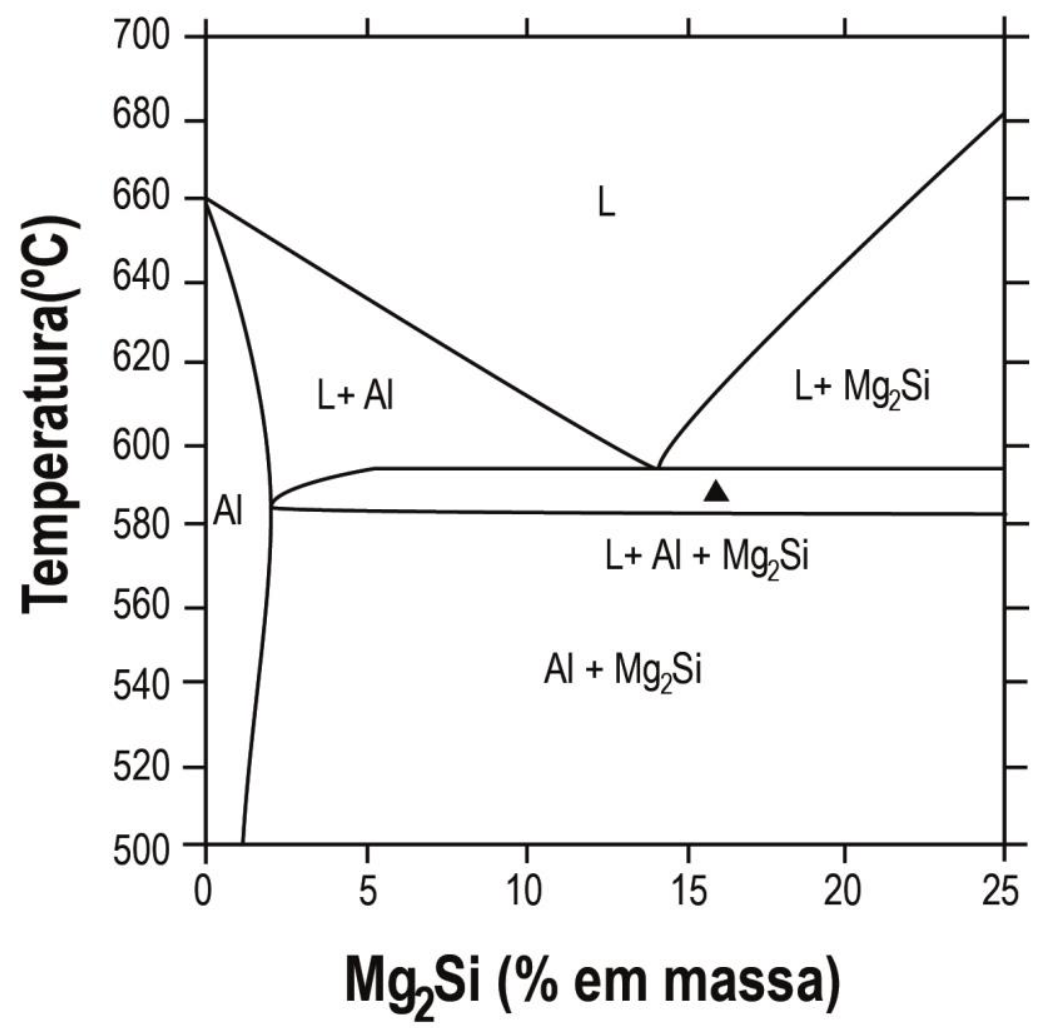

Figura 1: Sistema pseudo binário para as ligas do sistema Al-Mg-Si [1].

O ciclo térmico de endurecimento por precipitação da liga AA 6351 é composto de duas etapas: solubilização por volta de $500^{\circ} \mathrm{C}$ com resfriamento rápido até a temperatura ambiente e envelhecimento propriamente dito a $170^{\circ} \mathrm{C}$ por cerca de 6 horas. Devido aos teores de $\mathrm{Fe}$ e $\mathrm{Mn}$, é frequente detectada a presença na microestrutura desta liga da fase cúbica e incoerente (não causa endurecimento por precipitação) $\alpha-\mathrm{Al}(\mathrm{FeMn}) \mathrm{Si}$ [2].

No estado envelhecido artificialmente (T6) a liga AA 6351 apresenta resistência mecânica moderada, com limite de escoamento por volta de $285 \mathrm{MPa}$, ou seja, mais que o dobro das ligas de alumínio não tratáveis termicamente, tais como AA 3003 e AA 5052 no estado recozido, mas bem inferior ao das ligas AA 2024 e AA7075, que podem apresentar após envelhecimento limite de escoamento da ordem de 500 MPa. Por outro lado, a ductilidade e a conformabilidade da liga AA 6351 são 
significativamente superiores às das ligas 2024 e 7075, além de ser pouco susceptível à corrosão sob tensão. A plasticidade superior da liga AA 6351 possibilita a produção de produtos extrudados, tais como barras, arames, tubos e perfis [3]. Por apresentar uma combinação interessante de propriedades mecânicas, corrosão, usinabilidade e soldabilidade, a liga AA 6351 encontra numerosas aplicações na construção de navios, caminhões e ônibus, assim como em tubulações para óleo e gás [4].

O processo de extrusão possibilita a obtenção de perfis com geometrias complexas, dificilmente obtidas por meio de outros processos convencionais de conformação. Mais de um quarto (em massa) dos produtos semiacabados de alumínio são extrudados e cerca de $60 \%$ dos produtos extrudados de alumínio são de ligas da série AA 6xxx (Al-Mg-Si). Ligas de alumínio de todos os grupos ou séries podem em princípio ser extrudadas. Todavia, o processo de extrusão exige alta plasticidade do material a ser extrudado, limitando o número de materiais que podem ser conformados de maneira economicamente viável utilizando este processo. Deve-se mencionar ainda que a extrudabilidade não depende apenas do material, mas também de variáveis de processo [5,6]. Uma característica importante da extrusão é a distribuição bastante heterogênea da deformação ao longo da secção transversal do perfil, o que torna a obtenção de uma microestrutura homogênea, especialmente uma distribuição homogênea de tamanhos de grãos recristalizados, um desafio nem sempre atingido facilmente. A ocorrência de uma zona periférica de grãos grosseiros (Peripheral Coarse Grain; PCG) em perfis extrudados de alumínio é um evento relativamente frequente. A presença desta zona é um defeito superficial que tem consequências negativas na resistência mecânica, na resistência à fadiga, na usinabilidade, na resistência à corrosão, na resistência à corrosão sob tensão, na qualidade da superfície anodizada, na aparência estética e na susceptibilidade à formação, durante a posterior deformação plástica, do defeito superficial conhecido como casca de laranja $[7,8]$.

O objetivo principal deste trabalho é caracterizar a microestrutura de um tubo de parede grossa extrudado desta liga com auxílio de várias técnicas complementares de análise microestrutural, tais como microscopia óptica de luz polarizada, microscopia eletrônica de varredura eletrônica (MEV), espectroscopia de raios X por dispersão de energia (EDS), difração de elétrons retroespalhados (EBSD), medidas de dureza e de condutividade elétrica. A distribuição de tamanhos de grão e a eventual formação de uma zona periférica de grãos grosseiros receberão uma atenção especial.

\section{MATERIAIS E MÉTODOS}

\subsection{Material utilizado}

O material utilizado na pesquisa foi um tubo extrudado da liga AA 6351 com diâmetro interno de $175 \mathrm{~mm}$ e espessura de $22,5 \mathrm{~mm}$. Para a realização da análise química foi cortado do tubo um anel completo com largura de $12 \mathrm{~mm}$. A análise de composição química foi realizada na Companhia Brasileira de Alumínio (CBA), localizada em Alumínio, SP, utilizando um espectrômetro de emissão ótica (OES; Optical Emission Spectrometry) modelo ARL 3460. Para a realização das análises, a amostra foi usinada e lixada para a obtenção de uma superfície plana e isenta de irregularidades, contaminação superficial e de oxidação. Em seguida, a amostra foi posicionada no equipamento e a face preparada (lixada) recebeu a passagem de corrente, também chamada de queima, para emissão das radiações características 
de cada elemento e o equipamento fez a leitura, discriminação e quantificação. Foram realizadas três queimas e o resultado apresentado é sempre a média das três queimas, cujas médias são apresentadas na Tabela 1.

Tabela 1: Composição química (\% em massa) da liga AA 6351 determinada por OES

\begin{tabular}{|c|c|c|c|}
\hline Elemento & \% em massa & Elemento & \% em massa \\
\hline $\mathrm{Si}$ & 0,98 & $\mathrm{Na}$ & 0,0007 \\
\hline $\mathrm{Fe}$ & 0,224 & $\mathrm{Ca}$ & 0,0029 \\
\hline $\mathrm{Cu}$ & 0,032 & $\mathrm{Bi}$ & 0,0013 \\
\hline $\mathrm{Mn}$ & 0,449 & $\mathrm{Ga}$ & 0,009 \\
\hline $\mathrm{Mg}$ & 0,716 & $\mathrm{Zr}$ & 0,003 \\
\hline $\mathrm{Cr}$ & 0,000 & $\mathrm{Cd}$ & 0,0000 \\
\hline $\mathrm{Ni}$ & 0,000 & $\mathrm{Co}$ & 0,0002 \\
\hline $\mathrm{Zn}$ & 0,062 & $\mathrm{Li}$ & 0,0000 \\
\hline $\mathrm{Ti}$ & 0,022 & $\mathrm{Sr}$ & 0,0000 \\
\hline $\mathrm{V}$ & 0,003 & $\mathrm{Sb}$ & 0,0000 \\
\hline $\mathrm{Pb}$ & 0,0033 & $\mathrm{P}$ & 0,0005 \\
\hline $\mathrm{Sn}$ & 0,0003 & $\mathrm{Hg}$ & 0,0000 \\
\hline $\mathrm{B}$ & 0,002 & $\mathrm{Al}$ & 97,51 \\
\hline $\mathrm{Be}$ & 0,0000 & $\mathrm{Si}+\mathrm{Fe}$ & 1,20 \\
\hline $\mathrm{As}$ & 0,0000 & $\mathrm{Ti}+\mathrm{Fe}$ & 0,025 \\
\hline
\end{tabular}

A análise dos resultados da Tabela 1 revela que a composição química obtida mostra concordância com a especificação para todos os elementos químicos especificados e uma razão $\mathrm{Mg}$ :Si relativamente baixa $(0,731)$ [1].

\subsection{Caracterização do material como recebido}

As técnicas de caracterização microestrutural utilizadas são descritas sucintamente em seguida.

\subsubsection{Macrografia}

Para a análise macrográfica, a amostra foi inicialmente lixada e polida mecanicamente e em seguida atacada com solução de $33 \%$ de $\mathrm{H}_{2} \mathrm{O}, 33 \%$ de $\mathrm{HNO}_{3}$ e $33 \%$ de $\mathrm{HCl}$.

\subsubsection{Microscopia óptica de luz polarizada (MO)}

As amostras foram preparadas para análise no $\mathrm{MO}$ segundo a seguinte sequência: i) lixamento com lixas de carboneto de silício (SiC) de granulometria 220, 400, 800 e 1200; ii) polimento com suspensão de alumina, seguida por polimento em sílica coloidal; iii) anodização com solução de HBF4 1,8\% (solução de Barker), utilizando fonte 20V. Após a preparação descrita acima, as amostras foram analisadas no microscópio óptico com polarizador de luz, marca Olympus BX51M. 


\subsubsection{Microscopia Eletrônica de Varredura (MEV)}

Com auxílio do microscópio eletrônico de varredura (MEV), instalado no Departamento de Engenharia Metalúrgica e de Materiais da Escola Politécnica, foram realizadas observações e feitas imagens com elétrons secundários e retroespalhados e realizadas análises de espectrometria de raios $\mathrm{X}$ por dispersão de energia (EDS) e análise por difração de elétrons retroespalhados (EBSD). Para realização das análises por EDS, as amostras não foram atacadas, apenas polidas. Para realização das análises por EBSD, as amostras polidas mecanicamente foram adicionalmente polidas eletroliticamente com solução de 30\% de ácido perclórico em etanol, sendo a tensão aplicada de $30 \mathrm{~V}$ por 30 segundos.

\subsubsection{Dureza Vickers}

As medidas de dureza Vickers foram realizadas no Emcotest Durascan com carga de $200 \mathrm{~g}$. As medições foram realizadas tanto secção na longitudinal quanto na transversal, no centro e nas periferias interna e externa. Para a medição da variação de dureza ao longo da secção transversal do tubo foram feitas 81 medidas.

\subsubsection{Condutividade elétrica}

Para medição da condutividade elétrica foi utilizado um condutivímetro modelo DC$11 \mathrm{M}$ da marca Zappi, disponível no Departamento de Engenharia Metalúrgica e de Materiais da Escola Politécnica da USP.

\section{RESULTADOS E DISCUSSÃO}

Inicialmente foram realizadas medições de condutividade elétrica em 4 pontos na secção transversal e em 10 pontos na superfície externa ao longo do comprimento. Foram adicionalmente realizadas medidas em outras 6 pontos escolhidos aleatoriamente, totalizando 20 posições de medida. A média das medidas de condutividade elétrica realizadas em 20 posições da amostra foi de $47,4 \%$ IACS, equivalente a $27,51 \mathrm{mS} / \mathrm{m}$. O valor de condutividade elétrica da liga AA 6351 na condição T6 encontrado na literatura é de $46 \%$ IACS [3].

A dureza encontrada foi de $97,8 \mathrm{HV}$. O valor de dureza encontrado na literatura para a liga AA 6351 na condição T6 é de 100 HV [3]. A variação de dureza ao longo da espessura do tubo ao longo da seção transversal foi pouco significativa, sendo a periferia externa ligeiramente mais dura que a periferia interna (vide Figura 2). Ainda com relação às medidas de dureza, após tratamento térmico realizado a $470^{\circ} \mathrm{C}$ por 6 horas e a $480^{\circ} \mathrm{C}$ por 2 horas a dureza caiu para $58,8 \mathrm{HV}$ e $65,8 \mathrm{HV}$, respectivamente. Portanto, tanto as medidas de condutividade elétrica, como as medidas de dureza, sugerem que o tubo como recebido encontrava-se na condição envelhecida, com propriedades similares às da condição ou têmpera T6.

$\mathrm{Na}$ Figura 3 é apresentada a macrografia, mostrando a heterogeneidade na distribuição de tamanhos de grão ao longo da superfície externa do tubo. Esta zona periférica de grãos grosseiros recebeu atenção especial neste trabalho. 


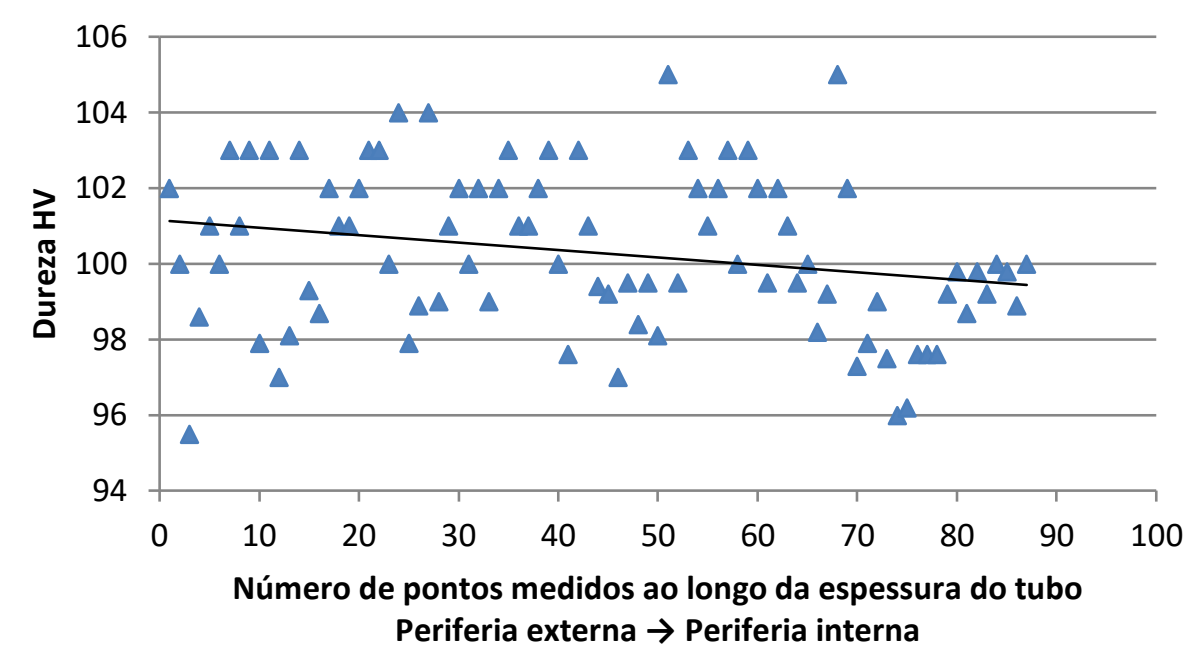

Figura 2: Variação da dureza Vickers ao longo da espessura do tubo.

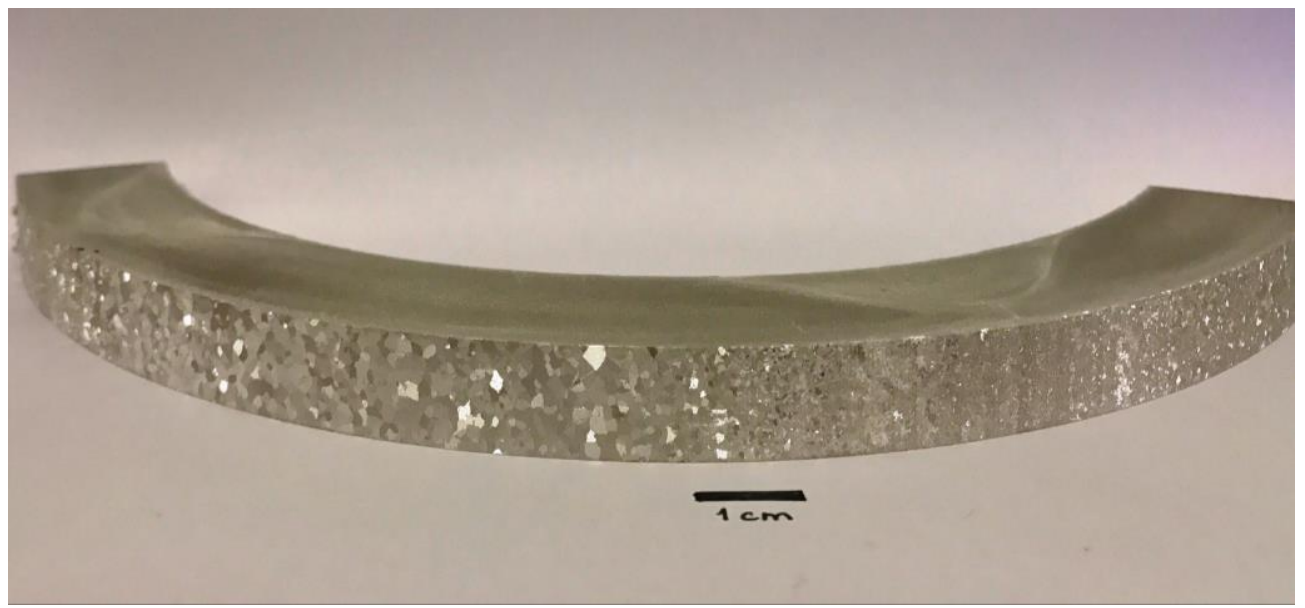

Figura 3: Macrografia da superfície externa do tubo, após ataque com $\mathrm{HCl}-\mathrm{HNO}_{3}-\mathrm{H}_{2} \mathrm{O}$.

A presença e as características os precipitados presentes foram estudadas com auxílio de microscopia eletrônica de varredura e espectroscopia de raios $\mathrm{X}$ por dispersão de energia (EDS). Na figura 4 são apresentados os precipitados maiores, alinhados, com interfaces irregulares e parcialmente facetadas.

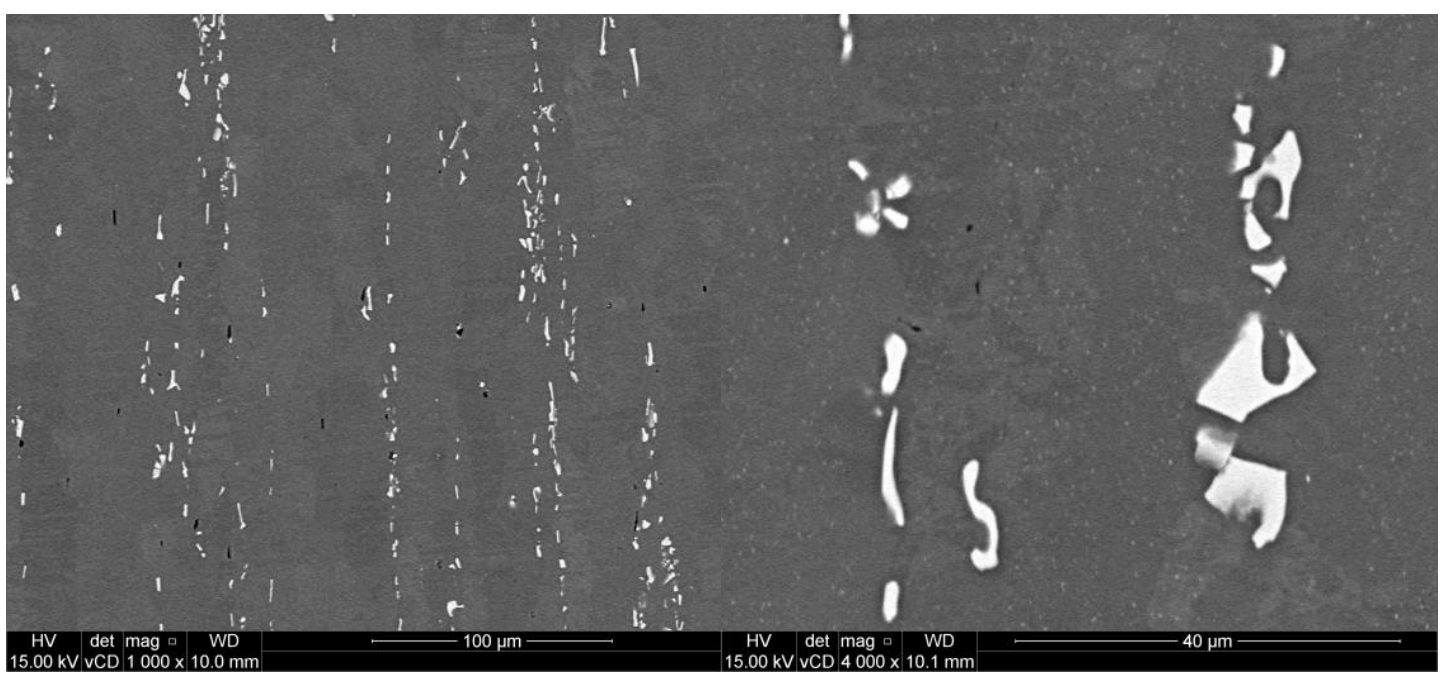

Figura 4: Imagens obtidas por microscopia eletrônica de varredura, com dois aumentos diferentes, dos precipitados maiores observados na liga. 
Uma análise mais detalhada da microestrutura utilizando MEV/EDS revelou a presença de três tipos de partícula (vide Figura 5). As partículas maiores já mencionadas e mostradas na Figura 4 continham $\mathrm{Al}, \mathrm{Fe}, \mathrm{Mn}$ e $\mathrm{Si}$ e são provavelmente partículas da fase $\alpha-\mathrm{Al}(\mathrm{FeMn}) \mathrm{Si}$ [2]. As partículas escuras, grandes e menos frequentes, eram ricas em $\mathrm{Al}, \mathrm{Mg}, \mathrm{Si}$ e $\mathrm{O}$. Já as partículas claras e bem mais finas não tinham dimensões suficientes para serem analisadas com EDS.
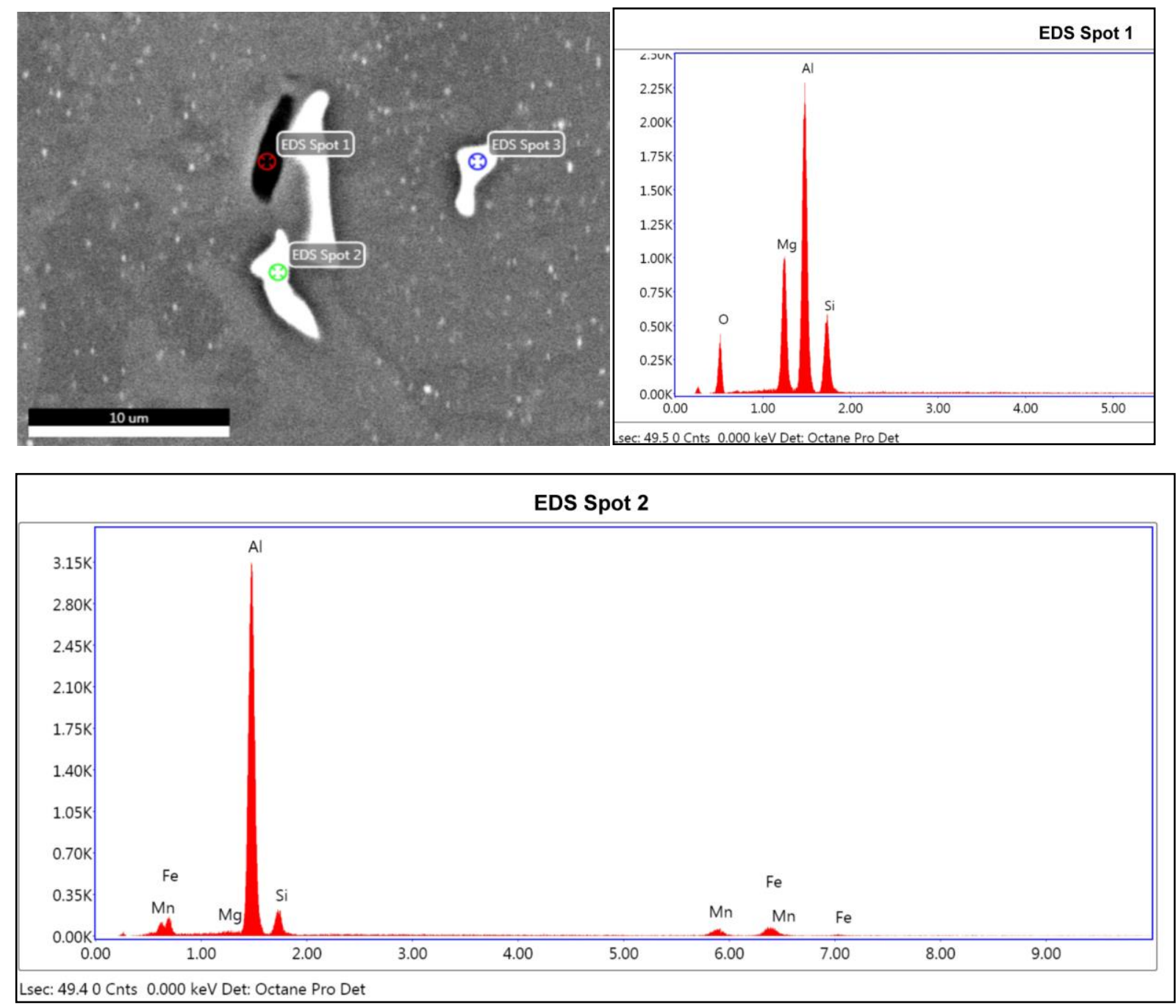

Figura 5: Na parte superior esquerda da figura são apresentadas imagens das partículas com os três pontos selecionados para análise com EDS. Na parte superior direita é apresentado o espectro da partícula escura do tipo, identificada como ponto 1 (spot 1). Na parte inferior da figura é apresentado o espectro da partícula identificada como ponto 2 (spot 2). O ponto 3 (spot 3) apresentou a mesma composição do ponto 2 .

Com auxílio de microscopia óptica de luz polarizada foi possível detectar a presença (vide Figura 6) de uma zona periférica de grãos grosseiros (Peripheral Coarse Grain; PCG) nas proximidades das superfícies externa e interna do tubo. A espessura da camada de grãos grosseiros, que não era contínua, variou de 200 a $600 \mu \mathrm{m}$. A formação de PCG está fortemente ligada à taxa de deformação. Na extrusão as paredes externas e internas são regiões com maiores taxas de deformação, ocorrendo, portanto, nessas regiões acúmulo de energia armazenada na forma de defeitos cristalinos, aumento de temperatura e maior tendência à ocorrência de recristalização $[7,8]$. 


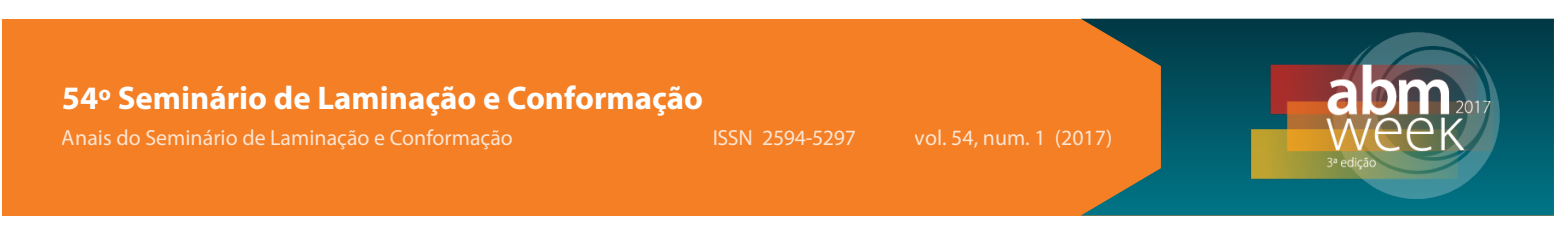

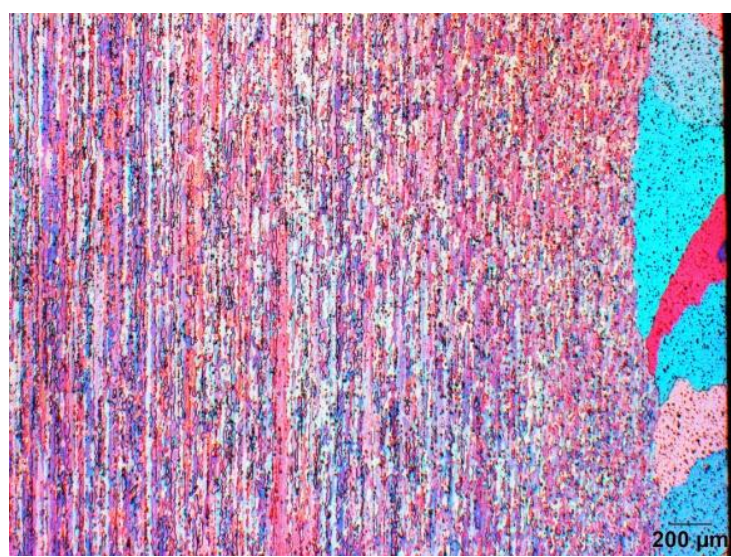

(a)

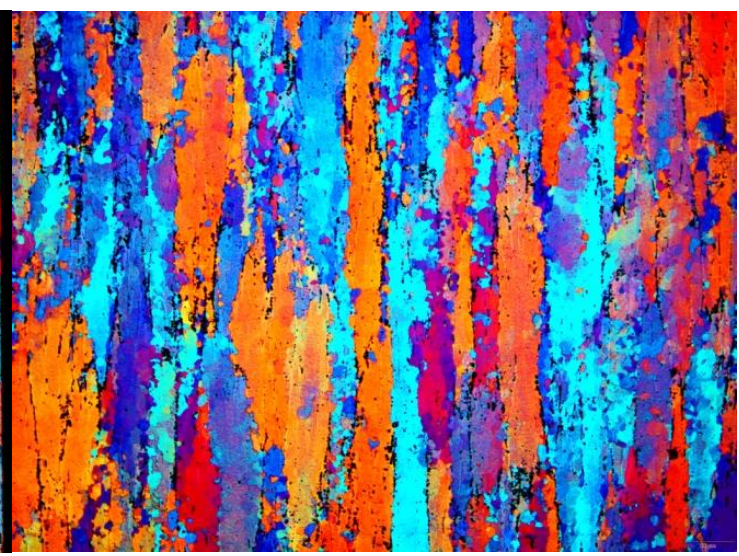

(b)

Figura 6: Microscopia óptica com luz polarizada após anodização com reagente de Barker: (a) periferia externa (aumento 20X); (B) região central da espessura (aumento 50X).

Eivani e co-autores [8] propuseram recentemente um modelo (vide Figura 7) para explicar a ocorrência de PCG. De acordo com o modelo desses autores [8], a formação de PCG ocorre na seguinte sequência: (a) microestrutura inicial de grãos equiaxiais; (b) formação de subgrãos durante a extrusão à quente; (c) redução no tamanho de sub grão com a continuidade da deformação e formação de microestrutura parcialmente recristalizada dinamicamente; (d) início da recristalização estática e formação de microestrutura parcialmente recristalizada; (e) crescimento normal de grãos recristalizados dinamicamente e crescimento anormal dos grãos recristalizados estaticamente; (f) microestrutura final composta de grãos finos e grãos grosseiros.

(a)

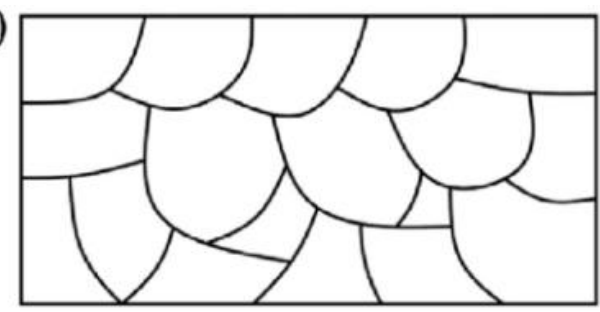

(c)

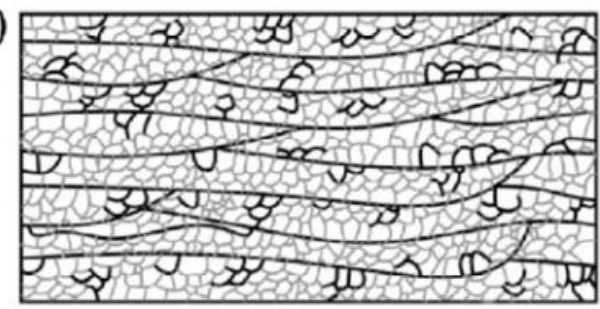

(e)

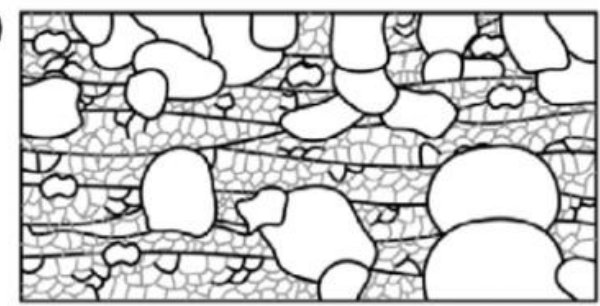

(b)

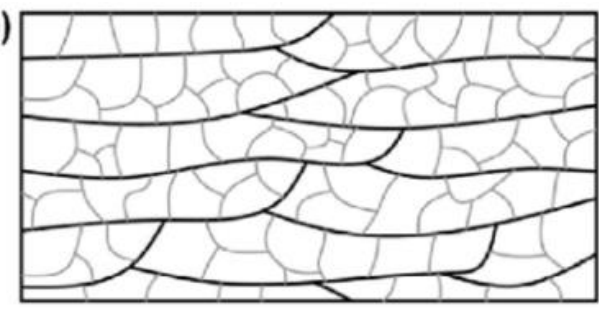

(d)

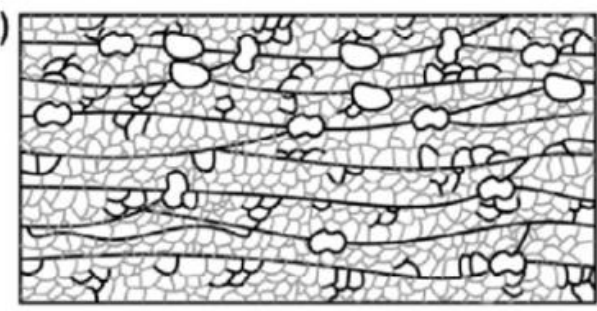

(f)

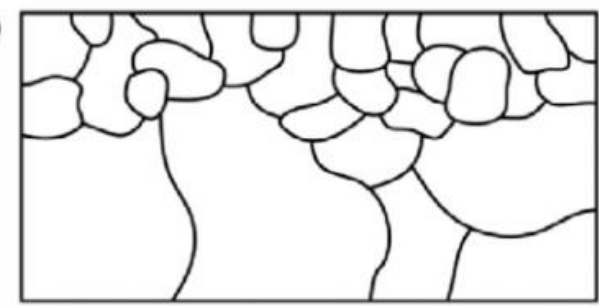

Figura 7: Sequência de formação de zona periférica de grãos grosseiros (Peripheral Coarse Grain; PCG) durante a extrusão de ligas de alumínio [8]. 
Em seguida, foi realizado um estudo com auxílio de EBSD visando detectar eventuais diferenças cristalográficas (microtextura), diferenças de orientação entre microrregiões vizinhas (mesotextura) e determinação de tamanho médio de grão em três regiões da secção transversal do tubo: externa; central e interna. Alguns resultados referentes às análises de EBSD são apresentados na Figura 8.
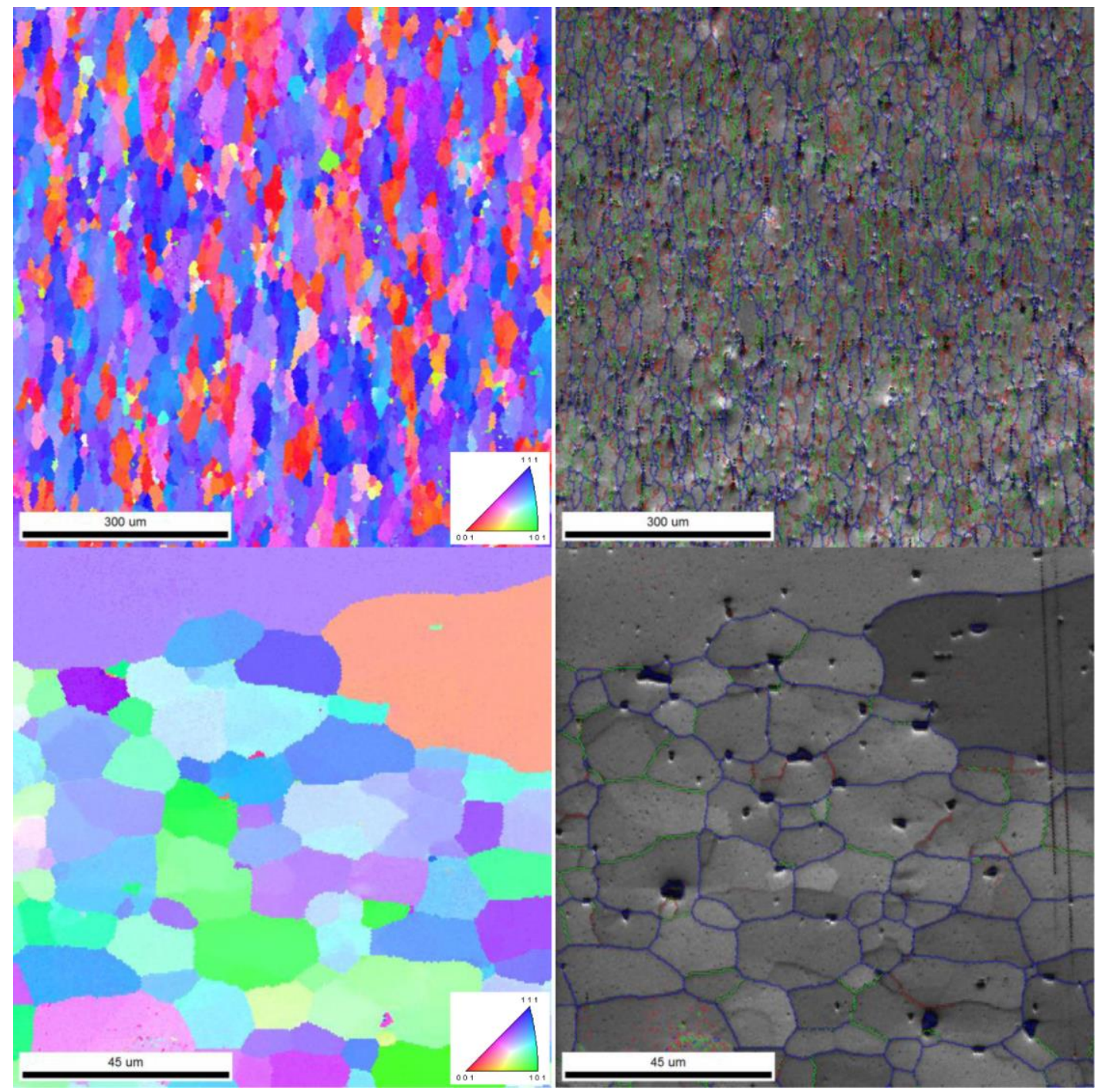

Figura 8: Análises por EBSD em duas regiões da secção transversal do tubo: região central na parte superior e superfície interna na parte inferior. Os aumentos das imagens não são iguais, conforme ilustram as barras, na parte inferior esquerda das figuras.

A simples análise visual das cores (cada cor representa uma orientação cristalográfica) das figuras do lado esquerdo do leitor na Figura 8 mostra que a textura varia ao longo da secção transversal do tubo. Ainda na Figura 8, do lado direito do leitor, são apresentadas análises do grau de desorientação entre os contornos de grão (mesotextura). Os contornos e subcontornos foram divididos em três classes de diferenças de orientação: entre 2 e $5^{\circ}$ (linhas vermelhas); entre 5 e $15^{\circ}$ (linhas verdes) e entre 15 e 180 (linhas azuis).

$\mathrm{Na}$ Tabela 2 são apresentados resultados de mesotextura obtidos em três regiões do tubo: superfície externa; central e superfície interna. 
Talela 2: Análise da diferença de orientação entre contornos (mesotextura) em três regiões da secção transversal do tubo: superfície externa; central e superfície interna

\begin{tabular}{|c|c|c|c|c|}
\hline $\begin{array}{c}\text { Diferença de } \\
\text { orientação }\end{array}$ & $\begin{array}{c}\text { Cor da linha ou } \\
\text { contorno }\end{array}$ & $\begin{array}{c}\text { Superfície } \\
\text { externa }\end{array}$ & Centro & $\begin{array}{c}\text { Superfície } \\
\text { interna }\end{array}$ \\
\hline 2 a 5 & vermelha & $20,3 \%$ & $31,4 \%$ & $15,5 \%$ \\
\hline 5 a $15^{\circ}$ & verde & $14,2 \%$ & $26,5 \%$ & $19,6 \%$ \\
\hline 15 a $180^{\circ}$ & azul & $65,4 \%$ & $42,1 \%$ & $64,9 \%$ \\
\hline
\end{tabular}

A análise dos resultados apresentados na Tabela 2 revelou que nas periferias interna e externa do tubo $65 \%$ dos contornos eram de alto ângulo enquanto que na região central apenas $42 \%$ eram de alto ângulo. Além disto, a presença de contornos de baixo ângulo era mais acentuada na região central. Isto significa que as periferias interna e externa estão mais recristalizadas que o centro da amostra, embora as medidas de dureza e de condutividade elétrica nessas regiões não tenham apresentado diferenças significativas. Nas regiões externa e interna do tubo, o grau de deformação (potencial termodinâmico para a recristalização) e o aumento de temperatura devido ao atrito durante a extrusão são maiores, ambos fatores contribuindo para uma recristalização mais acentuada e consequentemente para um maior amolecimento.

A média dos tamanhos de grãos na periferia externa, centro e periferia interna foi de $16,7 \mu \mathrm{m}, 34,7 \mu \mathrm{m}$ e $20,5 \mu \mathrm{m}$, respectivamente. Isto evidencia um maior acúmulo de defeitos cristalinos nessas regiões, com a formação de um número maior de núcleos de recristalização e menor tamanho de grão recristalizado nas regiões externa e interna, em comparação com o centro do tubo, onde o tamanho de grão é maior e ainda remanesce uma fração maior de contornos de baixo ângulo ou subcontornos.

\section{CONCLUSÕES}

O tubo apresentou valores de dureza e de condutividade elétrica típicas da condição T6. Não foram detectados defeitos macroscópicos de extrusão. Foram detectados dois tipos de precipitados; um rico em $\mathrm{Mg}$ e Si e outro rico em $\mathrm{Mn}$, Fe e Si. Um terceiro tipo, mais fino, não pode ser analisado por EDS. A distribuição de precipitados mostrou-se praticamente invariável ao longo da espessura. O mesmo não ocorreu com a distribuição de tamanhos de grão, com a orientação preferencial dos grãos (textura cristalográfica) e com fração de contornos de baixo ângulo (mesotextura). Foi detectada a presença de uma zona periférica de grãos grosseiros (Peripheral Coarse Grain; PCG) nas proximidades das superfícies externa e interna do tubo. A espessura da camada de grãos grosseiros, que não era contínua, variou de 200 a $600 \mu \mathrm{m}$. A ocorrência dessas zonas de grãos grosseiros pode ser explicada pelas maiores concentrações de defeitos cristalinos e temperatura mais elevada nessas regiões durante a extrusão.

\section{Agradecimentos}

Agradecemos aos colegas Mariana de Medeiros Ávila, Miguel Borodiak, Viviane Serrão da Companhia Brasileira de Alumínio (CBA) e Rafael Rocha Maia (EPUSPPMT) pelo apoio na preparação metalográfica e ao Departamento de Engenharia Metalúrgica e de Materiais da Escola Politécnica e seus técnicos pela ajuda e infraestrutura fornecidas durante a realização deste trabalho. 


\section{REFERÊNCIAS}

1 Zhu H, Couper MJ, Dahle AK. Effect of process variables on Mg-Si particles and extrudability of 6xxx series aluminum extrusions. JOM Journal of the Minerals, Metals and Materials Society. 2011;63(11):66-71.

2 Priya $\mathrm{P}$, Johnson DR, Krane MJM. Numerical study of microstructural evolution during homogenization of Al-Si-Mg-Fe-Mn alloys. Metallurgical and Materials Transactions A. 2016;7(9):4625-4639.

3 Davis, JR. ASM Specialty Handbook - Aluminum and Aluminum Alloys. 3rd edition. Ohio: ASM International; 1994.

4 Reddy MVN, Reddy MN, Kumar KV, Garre P. Experimental investigation of tensile strength on Al 6361 to the aerospace structural applications. International Journal of Mechanical Engineering and Technology (IJMET). 2014;5(2):110-114.

5 Altan T, Oh S-I., Gegel HL. Conformação de metais: fundamentos e aplicações. São Carlos: Publicação EESC-USP; 1999.

6 Helman H, Cetlin, PR. Fundamentos da conformação mecânica dos metais. São Paulo: Artliber Editora Ltda; 2005.

7 van Geertruyden WH, Browne HM, Misiolek, WZ, Wang PT. Evolution of surface recrystallization during indirect extrusion of 6xxx aluminum alloys. Metallurgical and Materials Transactions A. 2005;36(4):1049-1056.

8 Eivani AR, Zhou J, Duszczyk J. (2016). Mechanism of the formation of peripheral coarse grain structure in hot extrusion of Al-4.5Zn-1Mg. Philosophical Magazine. 2016;96(12):1188-1196. 